\title{
Workplace Bullying: Is It A Matter Of Growth?
}

Charles Chekwa, Troy University, USA

Eugene Thomas, Jr., Troy University, USA

\begin{abstract}
The issues surrounding workplace bullying have existed for quite some time, but the term itself and its definition are relatively new. To delve further into this topic, this research is intended to answer the question, "What is the perception of workplace bullying within the educated workforce?" The assertions presented will center on factors, impact to productivity, and management as they relate to bullying in the workplace. Additionally, where available, legislation that has been passed or proposed to protect businesses and individuals with regard to punitive controls and management of these behaviors has been reviewed. Last, factors will be introduced in reference to prey and predator as they correlate to responsibility in addressing workplace bullying itself.
\end{abstract}

Keywords: Harassment; Bullying; Workplace Bullying

\section{INTRODUCTION}

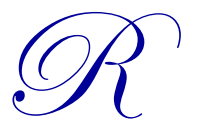

evised version JBER 9.10 uploaded One might assume that most, if not all, employees have felt unappreciated, ostracized, or even beleaguered within the workplace. The authors believe that there is substantiation for this line of thought. Thus, questions like "Why does my boss hate me?", "What did I do to deserve how I am being treated?", or "Can my problems be with me?" can be counterproductive in a work environment. With respect to the latter, the authors believe that one of the most important conversations we have every day is with ourselves. Described as self-talk, this phenomenon is responsible for determining whether our outlook is optimistic or pessimistic. Thus, the authors believe that when one is placed in a situation of bullying, particularly in the workplace, a negative impact is eminent.

In theory, the authors' expectation is that deterrents should be in place to negate this type of behavior, suggesting that more adept employees and leaders should both act as counteractions to bullying and themselves be immune to temptations to bully. With this in mind, the authors have delved further by seeking an answer to the question, "What is the perception of workplace bullying within the educated workforce?" In doing so, the authors have focused on the following questions: 1) What is workplace bullying?, 2) What is the impact of workplace bullying on productivity in the workplace?, 3) What is the difference between workplace bullying and harassment?, 4) What are the laws affecting and addressing workplace bullying?, and 5) How can workplace bullying be managed?

\section{WHAT IS WORKPLACE BULLYING?}

The authors employed the definition presented by Washington State Department of Labor \& Industries which describes workplace bullying as "repeated, unreasonable action directed toward an employee that is intended to intimidate, degrade, humiliate, undermine, or which creates a risk to health or safety of employee(s)." Wikipedia says that "psychopathic" and "social phobic" describe offender and potential outcome of workplace bullying, respectively. Furthermore, the Workplace Bullying Institute (WBI) has identified "workplace bullying" as a relatively new term that has a gray partition with the term "harassment." Lutgin-Sandvik elaborated by saying that "the lack of unifying language to name the phenomenon of workplace bullying is a problem because without a unifying term or phrase, individuals have difficulty naming their experiences of abuse and therefore have trouble pursuing justice against the bully" (Lutgen-Sandvik, Tracy, \& Alberts, 2006). 
Despite indistinguishable terminology, the WBI further unfolded this term to articulate that workplace bullying can also

include, but is not limited to, spreading malicious rumors, gossip, or innuendo that is not true; excluding or isolating someone socially; undermining or deliberately impeding a person's work; physically abusing or threatening abuse; removing areas of responsibilities without cause; constantly changing work guidelines or establishing impossible deadlines that will set up the individual to fail; under work - creating a feeling of uselessness, belittling a person's opinions, blocking applications for training, leave or promotion, and various others.

Additionally, and in addressing this behavior, the WBI has suggested that there can be opportunities for misdiagnosing and mismanaging violations. WBI identified the seriousness of the issue and recommended that complaints be investigated thoroughly. Suggestions by mental health professionals include the following:

- Don't tell clients "change your behaviors that provoke the bully".

- $\quad$ Trust what abuse victims tell you. Believe that there are people as evil as have been described to you.

- $\quad$ Stop holding targeted clients responsible for the unsolicited psychological violence they endure. Understand how work environments - not personal flaws - explain health-harming mistreatment. Stop committing the fundamental attribution error.

- $\quad$ Be careful not to misdiagnose as borderline or adjustment disorder. Minimize psychological testing during acute phases of abuse so as not to skew results.

According to http://www.bullyonline.org/workbully/bully.htm (n.d.), there are several types of bullying, including, but not limited to, the following:

- Institutional bullying is where it becomes a part of the culture or the norm.

- $\quad$ Client bullying is where employees are bullied by those they serve; e.g., teachers are bullied (and often assaulted) by pupils and their parents.

- $\quad$ Serial bullying is where the source of all dysfunction can be traced to one individual who picks on one employee after another and destroys them.

- Secondary bullying is mostly unwitting bullying which people start exhibiting when there's a serial bully in the department. The pressure of trying to deal with a dysfunctional, divisive, and aggressive serial bully causes everyone's behavior to decline.

- $\quad$ Pair bullying is a serial bully with a colleague. Often one does the talking while the other watches and listens.

- Vicarious bullying is where two parties are encouraged to engage in adversarial interaction or conflict.

- $\quad$ Cyber bullying is the misuse of email systems or Internet forums, etc. for sending aggressive flame mails.

\section{IMPACT ON PERSONNEL AND PRODUCTIVITY}

Absenteeism, turnover, higher insurance premiums, and litigation are but a few of the harmful impacts of workplace bullying on productivity, as stated by Drs. Gary and Ruth Namie, psychotherapists and co-founders of the Workplace Bullying Institute (http://www.workplacebullying.org). According to a Business Week article, "Stuck in Jobs: The New Swing Voters", an average of 1 million fewer Americans per month quit than in the previous year (Dorning, 2011). However, according to the 2010 WBI US Workplace Bullying Survey, 54 million workers are, or have been, bullied at work. Therefore, the authors hypothesized that despite workplace bullying having an impact on employee satisfaction with working conditions as they pertain to relationships, retention may be a non-factor. Furthermore, the authors surmised that economic conditions may even stimulate bullying behavior. With this in mind, the authors also asked the following questions: 1) How will the victim of bullying perform in the face of this torment?, 2) What about workmanship and output quality within a victim's daily function?, and 3) How much in hard revenue can we attribute to the causes and effects? 
As the Health Matters website puts it, "when workplace bullying is present, morale and productivity decline, turnover increases, and there is a toll on employees' physical and emotional health" (Unknown, n.d.). According Dr. Gary Namie, "employees who are bullied say they spend between 10 and 52 percent of their day fending off harassment instead of working". According to the Level Playing Field Institute, a loss of just 2\% in productivity at an average Fortune 500 company due to "unfair treatment," which includes bullying, costs in the neighborhood of $\$ 8$ million a year (Penenberg, 2008). From theage.com.au site, "one study by Work Cover in the ACT found that workplace bullying costs the Australian economy between $\$ 6$ and $\$ 13$ billion a year" (Adonis, 2009). There are also psychological costs. Again referencing the WBI and Dr. Namie, for employees, bullying is "psychological torture." Dr. Namie has suggested that it is not uncommon for bullying behavior to result in forms of post-traumatic stress disorder (PTSD) among victims. Dr. Namie's surveys have also found that $41 \%$ of bullying victims become depressed, 76\% report suffering from "severe anxiety", $84 \%$ experience sleep disruption, and $40 \%$ of victims who leave their jobs do so for health-related issues.

"There are also specific factors that might make your business more conducive to workplace bullying" (Adonis, 2009). Psychologist Keryl Egan stated that "[s]udden changes and instability, undefined work structures and procedures, and insufficient levels of communication and direction are all a fertile breeding ground for a bully to emerge." As a consequence, the authors submit that the term "going postal" is worth noting as a side impact of unaddressed issues. The documentary Murder By Proxy: How America Went Postal was released in September 2011. Experts participating in the film included criminologist, Alan Fox, and Northeastern University and forensic psychiatrist, Michael Weiner. Both stated in the film that most murder sprees have some basis in longterm persecution (or perceived persecution) of (by) the future shooter who believed there was no other way to get "justice" (http://www.workplacebullying.org/bullying-contrasted/).

\section{DIFFERENCE BETWEEN WORKPLACE BULLYING AND HARASSMENT}

The Advice Leaflet - Bullying and Harassment at Work: Guidance for Employees, when discussing workplace bullying and harassment, states that "these terms are used interchangeably by most people" (Unknown, n.d.). Actually, and from the leaflet, it is proposed that within the work environment, these terms have distinctions, with the main difference between workplace bullying and harassment being physicality, frequency, and the fact that most often harassment affects someone in a protected class. In essence, the authors deduce that anyone can be bullied within the workplace, and despite the lack of physicality, the authors believe that the harm from workplace bullying, although less identifiable at times, can potentially be far reaching.

The nature of harassment involves factors such as uninvited touching, intruding in one's personal space, and/or the damaging of one's possessions. A further differentiation of workplace bullying from harassment is that workplace bullying "is almost always emotional or psychological and it often involves verbal and/or written communication and actions. This elusive nature of workplace bullying makes it a great deal more toilsome to stop than harassment" (Cade, n.d.). In fact, the authors understood from this reference that workplace bullying by the predator, much akin to that experienced in adolescence, is unbiased in its targets and "would-be" bullies particularly target those they perceive as better than themselves. Cade indicated that "probably the best way to differentiate between the two is to remember that harassment is founded on discrimination, whereas bullying is based on jealousy and/or insecurity. It should be noted that only one instance of harassment is required to distinguish it as harassment".

\section{LEGISLATION}

Surprisingly, according to Workplace Bullying and Disruptive Behavior: What Everyone Needs to Know, "[b]ullying itself is not a crime in the US unless it involves harassment" relating to a protected class - e.g., race/color, creed, religion - (Brazas, n.d.). In fact, research has revealed that although this phenomenon is more common than the authors originally believed, legislation is very limited. On a state-by-state level, however, the authors found that strides are being taken to correct this legal shortfall.

According to the Adam Cohen case study, 
[w]orkers' rights advocates have been campaigning for years to get states to enact laws against Workplace Bullying and in May of 2010, they scored their biggest victory. The New York state senate passed a bill that would let workers sue for physical, psychological or economic harm due to abusive treatment on the job. Should New York's Healthy Workplace bill become law, workers who can show that they were subjected to hostile conduct - including verbal abuse, threats or work sabotage - could be awarded lost wages, medical expenses, compensation for emotional distress and punitive damages (Cohen, 2010).

According to this same reference, however, employers are fighting back, citing the potential for frivolous lawsuits. For example, the article also identified a 2008 case where the Indiana supremecourt struck a blow against workplace bullying when it upheld a $\$ 325,000$ verdict against a cardiovascular surgeon". (Note: The plaintiff's legal team had an expert on workplace bullying testify at trial.) As with European models, such as the Protection from Harassment Act 1997, workplace harassment claims must be "extraordinary" to succeed (Unknown, n.d.).

\section{MANAGING WORKPLACE BULLYING}

The 2010 WBI US Workplace Bullying Survey of more than 4,000 respondents stated that $35 \%$ of workers have experienced bullying firsthand; $62 \%$ of bullies are men; $58 \%$ of targets are women; women bullies target women in $80 \%$ of cases, and bullying is four times more prevalent than illegal harassment (2007). Also, according to an article Workplace Bullying: A Management Primer,

[b]ullies are most likely to be bosses - 81 percent by the WBI's measure - but some 14 percent of the tormentors are co-workers of a victim, and 5 percent of reported bullies actually badger their higher ups. Co-workers who witness bullying (and the WBI found that 97 percent are aware of bullying when it happens) shy away from helping. In 46 percent of the cases studied by the WBI (September 2007), colleagues abandoned the bullied co-worker, while 15 percent actually joined the bully to torment the victim (Penenberg, 2008).

Workplace bullying is best served by being managed by offender and target, as stated by the World Health Organization when it pointed out that "workplace health promotion" should be addressed as "the combined efforts of employers, employees and society to improve the health and well-being of people at work" (http://www.who.int/occupational_health). The authors believe that adjustments must involve a particular focus from the employer. This is specifically because, as a section of the WBI website called Poor Leadership, Inept Managers pointed out, "the majority of bullies (72\%) are bosses" (Unknown, n.d.). The article, "Poor Leadership, Inept Managers", indicated the following:

- $\quad$ Bullies derive most of their support from...HR. It's a club, a clique, which circles the wagons in defense when one of their own is accused.

- $\quad$ Some executives command bullies to target particular employees. Bullies are simply good soldiers following orders in a blind fashion.

- $\quad$ Supervisory training is nearly nonexistent. No budget. No time. Few good skills taught. OJT [on-the-job training] transmits bad habits.

- $\quad$ Executives blame the problem on a "few bad apples", deflecting blame for systemic causes and denying responsibility for systemic cures.

The authors assert that within workplace bullying, management should "deal with the problem in a problem-solving, rather than punitive, framework. Development of people's emotional intelligence skills is suggested as one way to help address the problem within such a framework" (Sheehan, 1999).

From the perspective of the article "Tackling Bullying in the Workplace", the target of workplace bullying also has responsibility. The article suggests that one should "1) Talk to someone you trust for support, 2) Do not accept blame for bullying behavior, 3) If possible, seek a private audience with the bully as they may not realize their effect on you, 4) Keep journal of details to bullying behavior, and 5) seek help from intervening authority" (Brown, 2011). 


\section{FINDINGS/RESULTS}

Our approach to research within the area of workplace bullying was through a self-administered survey entitled "Workplace Bullying". The questionnaire was distributed to the respondents after endorsement and pretesting. The formal study began with the question, "In your opinion, is there a difference between bullying and harassment?" to establish a foundation for understanding the topic of the survey. Our population comprised adult working online students at Troy University without consideration of sector; we randomly selected a sample size of 50. Respondents indicated that the most common forms of workplace bullying "experienced" or "having knowledge of" were "excessive monitoring or micro-managing" and "exclusion or social isolation", respectively.

When asked "In your opinion, is there a difference between bullying and harassment?", $47 \%$ versus $43 \%$ of respondents indicated that there was no difference. When respondents with full-time employment status were asked about their perception of concern about workplace bullying within their workplace, $68 \%$ rated their employers' concern as average or less by selecting a rating of less than or equal to " 3 ". Of the full-time respondents, $72.7 \%$ of females versus $50.1 \%$ of males shared the perception of "average or less" concern about bullying in their workplace by selecting " 3 " or less as their response, with a mean response of 2.35 . However, $37 \%$ of respondents stated that they had taken one or more days off due to stressful relationships at work and $73 \%$ indicated that, given a better economy, workplace bullying would be the deciding factor for job change. From this, the authors concluded that socio-economic conditions do in fact affect decisions and perceptions associated with workplace bullying and worker willingness or unwillingness to endure unfavorable work environments. The authors believe that reporting perception may also be impactful as well.

As respondents' work experience increases, the perception of a positive outcome from reported bullying decreases; $84 \%$ of respondents with 10 years or less of experience - versus $16 \%$ with 11 or more years of experience - indicated a positive value of "most times" to "always" when incidents were reported. Additionally, $62 \%$ of the respondents said they would report workplace bullying if they recognized it and 67\% indicated that they would report these acts to human resources (HR), the manager, or the supervisor.

\section{CONCLUSION}

The authors' perceptions indicate that focus is insufficient at this point to adequately address workplace bullying. In the US, "[w]orker abuse is a widespread problem — in a 2007 Zogby poll, 37\% of American adults said they had been bullied at work - and most of it is perfectly legal" (Cohen, 2010). Additionally, research has revealed that $68 \%$ of respondents rate their employers' concern as average or less. From the authors' perspective, this merely presents an opportunity to stimulate fear within the victims and mask the existence of workplace bullying. Variables such as economic condition and internal networks further complicate matters. To validate this hypothesis, comments such as "managers/supervisors have personal relationships with upper management and HR" and "too often the power hierarchy is a part of it" make employee reluctance to unveil their issue as the victim more commonplace. Conversely, those who responded "Yes" pointed out that "if it is not reported, then there is no awareness of the situation and it may/will continue." The authors' initial hypothesis was tested on the idea of whether workplace bullying decreases as information is disseminated and worker experience increases.

Evidence within chi square validation revealed a contradiction to this theory. Comparative statistics have suggested that we failed to reject our null hypothesis $\left(\mathrm{H}_{0}\right)$. However, this has no bearing on the continued existence of workplace bullying. As secondary data suggest, other variables, such as economic instabilities, must be taken into account as they too affect decisions on attitude and decisions to walk away.

Lastly, workplace bullying and harassment bear resemblance; each deserves its own focus. As evidenced by the lack of legislation and clear language, the authors have shown that workplace bullying is not well understood and is most deserving of attention. Thus, the authors conclude that, like harassment, bullying has no place in the workplace. In addition, although the presented research is informative and supportive of this notion, it is also inconclusive and suggests that more in-depth research should be pursued. 


\section{AUTHOR INFORMATION}

Charles Chekwa is a graduate of Mississippi State University. He holds a BS degree in Accounting. His advance Degrees include MBA and DBA respectively. In addition to authoring a number of college level textbooks, he has extensive publication record in National and International journals. He has served as Dean of several colleges of business. He was the founding President of Diversified Business Consultants. He is currently a full professor of business at Sorrell College of business, Troy University. E-mail: cchekwa@ troy.edu (Corresponding author)

Eugene Thomas completed Master's degree from Troy University in 2010 after 5 years of service to Dillard University, New Orleans. At Dillard, he developed faculty and staff workshops that strengthened competencies in technologies and applications; he also served as the technical lead and coordinator for on-campus laboratories. Eugene also served as a part of an Executive Loaner Program with the United Way of Northeast, as a Community Builder. (He was CB of the Year for 2009).

\section{REFERENCES}

1. Adonis, J. (2009, September 15). How do you manage a workplace bully? Retrieved from http://www.theage.com.au/small-business/coaching/how-do-you-manage-a-workplace-bully-20090911fkgk.html\#ixzz1oN0hYDt6

2. Brown, B. (2011, June 23) Tackling bullying in the workplace. Community Practitioner, 84.6:45. Health Reference Center Academic.

3. Cade, V. (2011). Workplace bullying vs workplace harassment - The real facts you need to know. JDT Unbound. Retrieved from http://www.jdtunbound.com/unbound-exclusive/april/2009/workplace-bullyingvs-workplace-harassment-real-facts-you-need-know

4. $\quad$ Cohen, A. (2010, July 21). New Laws Target Workplace Bullying. Retrieved from http://www.time.com/time/nation/article/0,8599,2005358,00.html

5. Dorning, Mike. (2011, June 16). Stuck in jobs: The new swing voters. Retrieved from http://www.businessweek.com/magazine/content/11_26/b4234035499590.htm

6. Lutgen-Sandvik, P., Tracy, S. J., \& Alberts, J. K. (2006) Nightmares, demons and slaves: Exploring the painful metaphors of workplace bullying, Retrieved from http://en.wikipedia.org/wiki/Workplace bullying\#cite note-nightmares-0

7. Penenberg, A. L. (2008, October 20). Workplace bullying: A management primer. BNET. Retrieved from http://www.bnet.com/article/workplace-bullying-a-management-primer/242718

8. Sheehan, M. (1999) Workplace bullying: Responding with some emotional intelligence. International Journal of Manpower, Vol. 20, No. 1/2, pp. 57-69.

9. Unknown. (n.d.). Why employers do so little. Retrieved from http://www.workplacebullying.org/individuals/problem/employer-reaction/

10. Unknown. (n.d.). Advice leaflet - Bullying and harassment at work: Guidance for employees. Retrieved from http://www.acas.org.uk/index.aspx?articleid=797

11. Unknown. (2008, Dec. 17). Difference between bullying and harassment in the workplace. Filed under Bullies and Adults. Retrieved from http://www.grababullybythehorns.com/bullies-and-adults/differencebetween-bullying-and-harassment-in-the-workplace/

12. Unknown. (n.d.). Protection from Harassment Act 1997: Workplace harassment claim must be "extraordinary" to succeed. Retrieved from http://www.lexology.com/library/detail.aspx?g=5faef830-91bb4d06-a7ef-3e8b392671ec

13. Unknown. (2011, April 11). Eliminate bullying at work. Health Matters Newsletter. Retrieved from http://www.kingcounty.gov/employees/HealthMatters/Newsletter/April2011/StressLess.aspx 